\title{
Evaluation of Design and Simulation of Creep Test Rig for Full-Scale Crossarm Structure
}

\author{
M. R. M. Asyraf $\mathbb{D},{ }^{1}$ M. R. Ishak $\mathbb{D},{ }^{1,2,3}$ S. M. Sapuan, ${ }^{4}$ N. Yidris, ${ }^{1}$ R. A. Ilyas, ${ }^{4}$ M. Rafidah, ${ }^{5}$ \\ and M. R. Razman ${ }^{6}$ \\ ${ }^{1}$ Department of Aerospace Engineering, Universiti Putra Malaysia, 43400 UPM, Serdang, Selangor, Malaysia \\ ${ }^{2}$ Aerospace Malaysia Research Centre (AMRC), Universiti Putra Malaysia, 43400 UPM, Serdang, Selangor, Malaysia \\ ${ }^{3}$ Laboratory of Biocomposite Technology, Institute of Tropical Forest and Forest Product (INTROP), Universiti Putra Malaysia, \\ 43400 UPM, Serdang, Selangor, Malaysia \\ ${ }^{4}$ Advanced Engineering Materials and Composites Research Centre, Department of Mechanical and Manufacturing Engineering, \\ Universiti Putra Malaysia, 43400 UPM, Serdang, Selangor, Malaysia \\ ${ }^{5}$ Department of Civil Engineering, Universiti Putra Malaysia, 43400 UPM, Serdang, Selangor, Malaysia \\ ${ }^{6}$ Research Centre for Sustainability Science and Governance (SGK), Institute for Environment and Development (LESTARI), \\ Universiti Kebangsaan Malaysia, 43600 UKM, Bangi, Selangor, Malaysia
}

Correspondence should be addressed to M. R. M. Asyraf; asyrafriz96@gmail.com and M. R. Ishak; mohdridzwan@upm.edu.my

Received 10 August 2019; Revised 28 January 2020; Accepted 20 March 2020; Published 30 April 2020

Academic Editor: Jiang Jin

Copyright (c) 2020 M. R. M. Asyraf et al. This is an open access article distributed under the Creative Commons Attribution License, which permits unrestricted use, distribution, and reproduction in any medium, provided the original work is properly cited.

\begin{abstract}
A simulated model was developed in order to design and simulate the mechanical properties of a cantilever beam creep testing rig for a full-scale size crossarm in transmission towers. Currently, the Malaysian power grid system is implementing several materials, such as Chengal wood, polymeric composite, and galvanised steel, as crossarm structures. However, there is a lack of study regarding the long-term mechanical behaviour of heavy structures in the literature. Hence, this article explains the design development of creep test rig for a full-scale crossarm structure using CATIA and mechanical simulation (deformation and safety factors) of the product via ANSYS. The test rig will be used to predict the creep life of the cantilever beam structure. In this study, a tall and large base area structure was designed and replicated from an actual tower to elevate the crossarm above the ground level. In order to select the best performance model, a baseline conceptual test rig was generated in CAD modelling, and the finite element analysis was carried out by using a static structural analysis in ANSYS. Four different bracing configurations were incorporated in the baseline model, and the modified structures were then analysed. The results show that the hybrid bracing configuration has enhanced the mechanical properties and safety factors in the baseline model.
\end{abstract}

\section{Introduction}

The creep phenomenon occurs on a solid material that deforms permanently in a slow process under constant stress $[1,2]$. It transpires due to prolonged, constant stress that is applied to the material below its yield strength. Hence, it is exposed to deformation of the material structure since static load is continuously acting on it $[3,4]$. Moreover, large deformations may occur due to exposure in a higher magnitude of applied stress and longer period of time [5-7]. Consequently, it will contribute to the mechanical failure of the material, including excessive deflection, crack propagation, as well as wear and tear. For instance, moderate creep can possibly induce a cracking phenomenon that subsequently changes the behaviours and properties of a material structure [8]. Consequently, this leads to an operational dysfunctional, as it cannot fulfil its purpose through its mechanical and structural behaviours [9-11]. Therefore, the understanding of the creep phenomenon is crucial to ensure long service life of the 
current crossarm that is expected to be in service for more than 24 years of operation [12].

The current crossarm is mainly composed of Chengal wood (Neobalanocarpus heimii) and has been operating in a $132-\mathrm{kV}$ transmission tower since 1963 . The wooden-based material is selected based on its outstanding performance in terms of mechanical properties and arc quenching in lightning protection devices [13-16]. However, a study in the late 1990s has demonstrated that a matured Chengal wood has a lower mechanical performance as a crossarm $[17,18]$. In addition, more studies have proven that the old wood crossarm began to experience a failure after 24 years of service due to aging factor. According to Liew, the finding showed a defective wood crossarm that was found after only 14 years of service [19]. This happened due to the natural defects in timber, as the wood was exposed to a continuous operation in a prolonged period of time. As discussed earlier, there is an urgency in finding the alternatives for wood crossarm to cater these problems based on previous reports. To fulfil the requirements of these alternatives, a team of researchers have studied on introducing glass fibre-reinforced polymer (GFRP) composite crossarm into these towers to replace the current crossarm used [20]. This is because the polymeric material has a better mechanical performance that is capable of sustaining in longer time duration [16, 21-23].

A large number of numerical simulations were conducted to obtain the theoretical data of the properties of composite crossarm [24, 25]. In addition, several experimental studies were also carried out by using coupon specimens of composite crossarm material to identify these properties [26, 27]. Despite the extensive literature on coupon tests of composite crossarm, the studies on full-scale crossarm are still lacking. Hence, there is a need to perform the mechanical analysis on an actual composite crossarm to have a holistic view of their properties. Composite crossarms are still comparatively new to the market in comparison to their predecessors (wood and steel), and their service life in transmission towers is yet to be fully explored. Performing the creep analysis on a full-scale product can eliminate various exaggerated factors that are usually incorporated in structural designs with lower scale limits. Moreover, the product geometry and material profile may be ignored in these coupon tests. This is due to the coupon scale test is only compute the test in single parameter and condition without understanding full potential of the structure [28]. Therefore, to fully understand the creep properties and obtain a more reliable prediction of the service life of composite crossarm, mechanical tests on actual-scale crossarm structures are crucial. To perform various mechanical analyses, a test rig that is specifically built for actualsized composite crossarm is required [29]. The creep test will help obtain the bending strain and stress. These properties can aid in evaluating the life expectancy of the composite crossarm. In addition, the study of deflection and deformation of member components of the crossarm will also provide a more intuitive and holistic view in predicting the creep behaviour of the whole structure [30].

In this study, a test rig base model will be designed using CATIA software. This baseline model will consist of only braced frames, where it will be analysed using FEA. Moreover, various other bracing systems will be adopted in this model to enhance the structural performance of the test rig. Furthermore, these conceptual designs will be analysed using FEA for comparison purposes. This article will cover the simulation modelling and analysis of various designs of the test rig. Instruments that are needed in the test rig and for calibration of the complete test rig will also be discussed in this paper.

\section{Methodology}

The methodology explains the three stages involved in this work: design module, premodule, and static structural module. Figure 1 displays a clearer picture of the structural optimisation of creep test rig.

The modelling of the test rig configuration is developed based on the fundamentals of brace frame and bracing systems. In the preliminary design stage, five design configurations of the test rig were proposed for final evaluation. These designs followed the basic theories of bracing on other structural elements, such as bridge and building, among others. Initially, a benchmark model with the simplest design is proposed for other configurations, which used the concept of brace frame system. Based on several relevant literature works, several bracing systems, such as single diagonal, cross bracing, and V-bracing, are listed for their application in these test rig configurations [31-33]. Then, these bracing systems were integrated with the benchmark model to form single diagonal, cross bracing, and V-bracing models to be tested in the FEA. To improve these existing models, these bracing systems were combined and incorporated in the brace frame model to form a hybrid configuration. This model will be compared and analysed in terms of its performance with other structural designs. All configurations were simulated in the FEA for comparison and to select and fabricate the best model. The simulation was conducted in ANSYS, specifically in static structural analysis, to verify and validate its mechanical behaviour and safety performance.

\section{Design Module}

In order to fulfil the requirement for developing a creep test rig, a baseline CAD modelling is essential in this stage. For this purpose, a CAD modelling software tool, CATIA V5, was used to set the dimensions of the design. The total length of the test rig was determined at $5.43 \mathrm{~m}$ and the height was $4.10 \mathrm{~m}$, all of which were generated in the CAD modelling. The specific height was chosen based on a consensus achieved in a brainstorming session after going through the relevant literatures. Souza Pippi et al. reported that most transmission towers are designed and fabricated in the form of latticed steel structure to transmit a high-voltage current to the consumers [34]. In the last few decades, the latticed steel transmission tower was used in the transmission grid due to its better mechanical strength and greater structural integrity. The transmission tower is made up of steel frame with truss systems, where the angled members support the compression and tension loads. Other literature also stated 


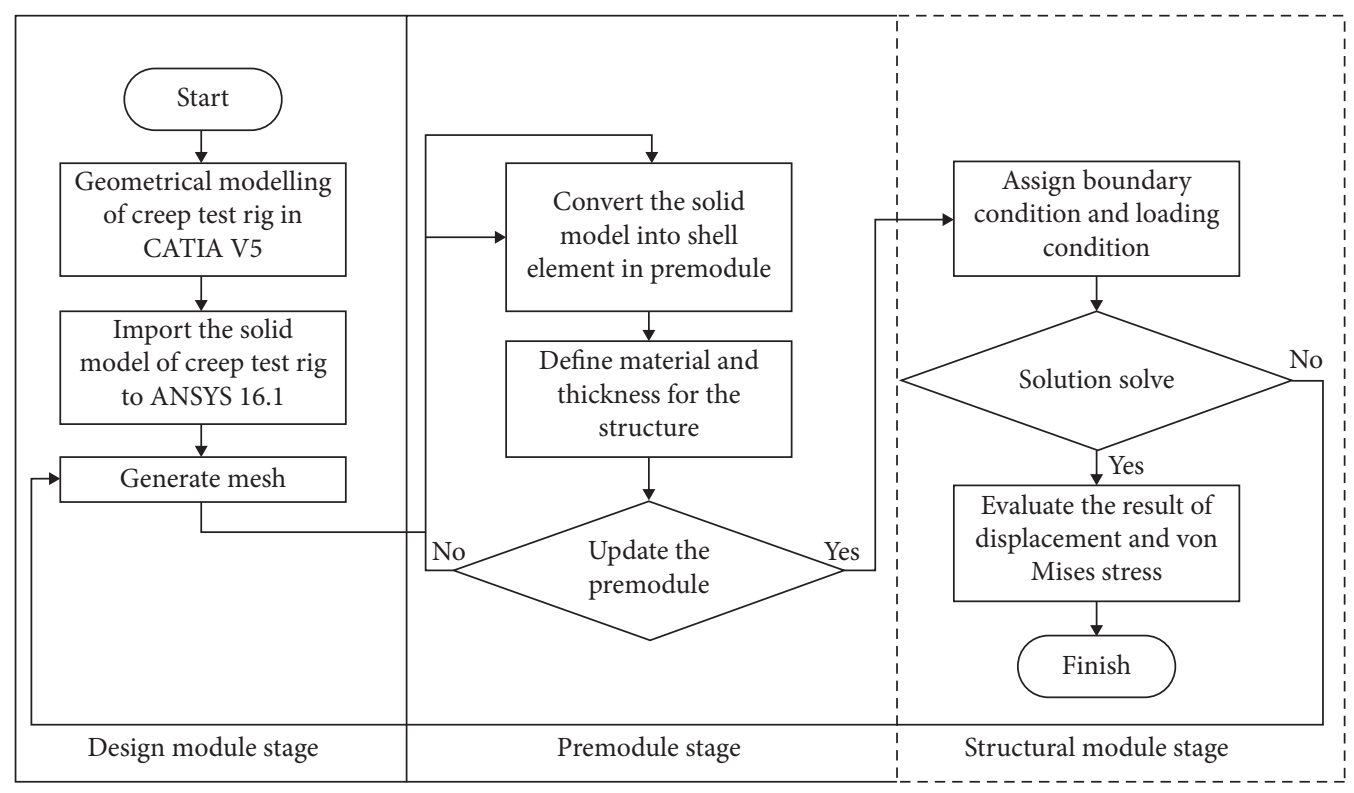

FIgURE 1: Flowchart of structural optimisation of creep test rig.

that the height of transmission towers, especially for $132-\mathrm{kV}$ towers, is generally between $60 \mathrm{~m}$ and $100 \mathrm{~m}$ [35-37]. Additionally, the transmission towers are usually heavy, since it has to support the heavy electrical cables and other external loads. To construct a test rig for an actual crossarm, the material should be selected based on the length and width of the existing 132-kV transmission tower. Since the height of a crossarm is roughly 2 to $3 \mathrm{~m}$, the test rig should be designed to have a height of roughly $4 \mathrm{~m}$ to replicate the actual condition in a smaller scale [38-40]. Figure 2 displays final CAD drawing of cantilever beam creep test rig for crossarm using CATIA V5.

\section{Concepts}

The presented concept of test rig will employ the cantilever beam test, as shown in Figure 3. For the main structure, it is made up of two parts: tower (a) and base (b). Moreover, the fittings (c) and measuring instrument $(\mathrm{d})$ are associated with the test specimen to be mounted on the test rig.

4.1. Tower Frame. The tower part functions to maintain the position of the crossarm at $4 \mathrm{~m}$ high from the ground. This will help the rig to perform the creep cantilever beam test on the crossarm at an elevated height, replicating its service life operation at a smaller scale [41]. This component is designed by using a low carbon steel alloy frame with bracing systems. The system allows the frame structure to sustain and support the high stress loading (compression and tension) while distributing the load to the bracing members [42].

4.2. Test Rig Base. Apart from the tower design, the test rig will also be supported by a base component. This will help maintain the whole assembly in a stable and upright position, while preventing any stability failures. The base is made of low-carbon steel alloy, and it extends in the direction of

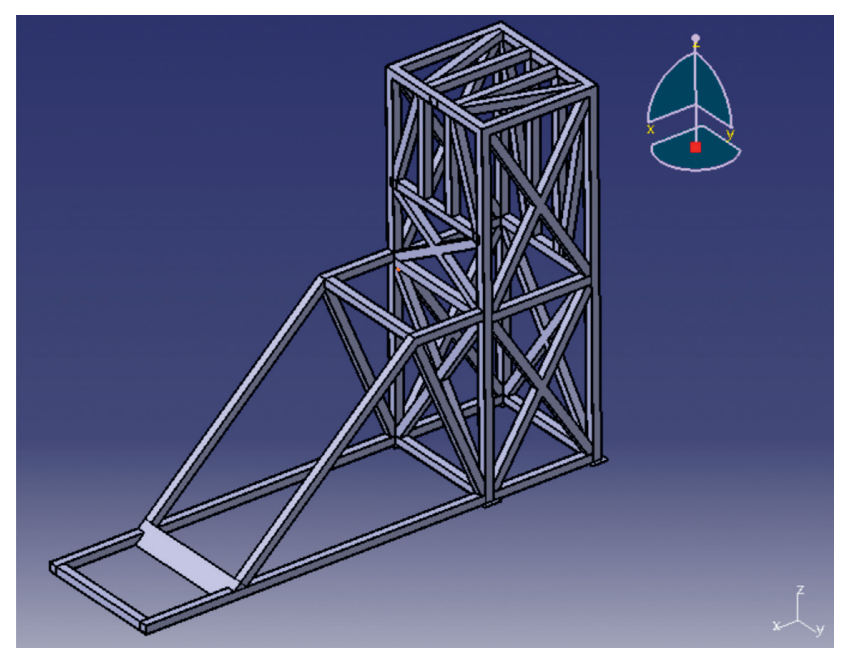

Figure 2: Final creep test rig design for actual $132 \mathrm{kV}$ composite crossarm.

the crossarm specimens to provide stability and avoid the rig from toppling when heavy and full-scale specimens are loaded.

\section{Structural Configuration for Creep Test Rig}

As mentioned in the previous section, the major structural components of the creep test rig include the tower and base parts. These structures are made up of individual member of square hollow section. The attachment of each member is connected by an arc welding, whereby this type of joint is considered as a continuous member without any constraint measures.

5.1. Mesh Generation. The accuracy of predicting the actual behaviour from the finite element model can be obtained by finite element mesh. The model is segmented into smaller 


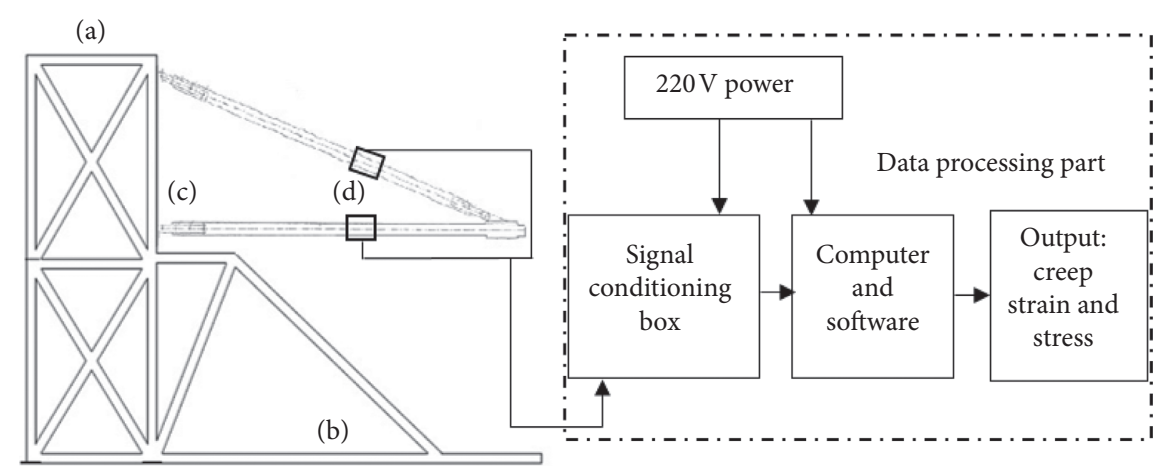

Figure 3: Concept of the test setup.

elements that are subjected to mesh refinement. It is essential to generate mesh in order to validate the finite element model analysis for the test rig structure. To produce a good mesh, there are guidelines to ensure the accuracy of the obtained results, where the following criteria are met [43]

(i) The mesh has to denote the geometrical areas and loads accurately

(ii) The mesh should sufficiently represent the large displacement or stress concentration in the generated solution

(iii) The mesh must contain elements that are sufficiently small and in an expected ratio

In this study, it has been found that the total number of elements used in the finite element analysis was less since the creep test rig was of symmetrically design. Subsequently, the mesh grid generation for the model was performed using mesh function in the ANSYS structural analysis. A body sizing with an element size of $50 \mathrm{~mm}$ was executed in a slow transition during meshing. Moreover, a smoothing effect was performed to ensure the simulated result is accurate. Subsequently, a mesh was generated in a form of triangle shape to define the stress concentration area, particularly in intricate profiles. Around 592,556 elements with corresponding 907,552 numbers of nodes were created in the simulation to produce accurate results, as shown in Figure 4.

5.2. Premodule. The subsequent stage in the finite element simulation was the premodule stage, where the overall process of constructing creep test rig was carried out in the ANSYS Workbench 16.1. The geometrical model has been updated in the form of shell model.

5.3. Static Structural Module. The static structural module is a necessary part, where the creep test rig design will be analysed to determine the structural response subjected to the structures to external influence of applied load. Several assumptions should be made prior to performing the analysis [44]:

(i) The test rig material is isotropic and has homogenous properties

(ii) The material has a linearly elastic structure

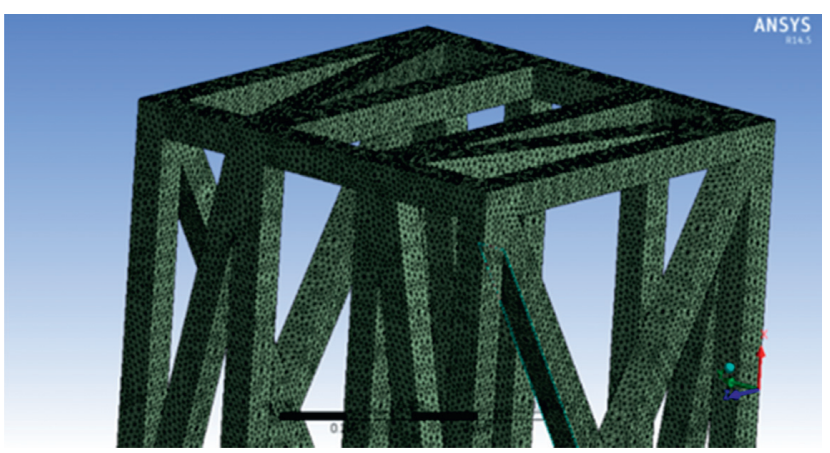

Figure 4: Mesh elements for the test rig analysis.

(iii) Deformation is continuous and small in the acting force areas

In this work, the test rig is designed in a form of shell element in ANSYS. A constraint condition is defined at the bottom surface of the model, where it is positioned as a fixed support, as displayed in Figure 5. In addition, the loading conditions are installed in the simulation at the connection points of the test rig and the crossarm. Table 1 demonstrates the loading conditions of a full-scale crossarm in a $132-\mathrm{kV}$ transmission tower.

In this stage, the material of the creep test rig will be defined based on the material used and the thickness of the structural member. There are no intricate components in the structure, which made the structure easier to be simulated. Furthermore, the structure had fully used a low-carbon steel, and the assignment replicated the actual fabrication of steel structure test rig. Moreover, the structural member of the test rig had implemented square hollow section with a cross section dimension of $100 \mathrm{~mm} \times 100 \mathrm{~mm} \times 1.9 \mathrm{~mm}$. The material properties of the used items are tabulated in Table 2.

\section{Results and Discussion of Simulation Studies}

The test rig configurations are designed according to the integration of actual dimensions of crossarm and the fundamental of the truss systems. Hence, to have an appropriate design configuration, several listings of bracing types have been created. For the first configuration, the basic brace frame was created as a benchmark model in the design series 


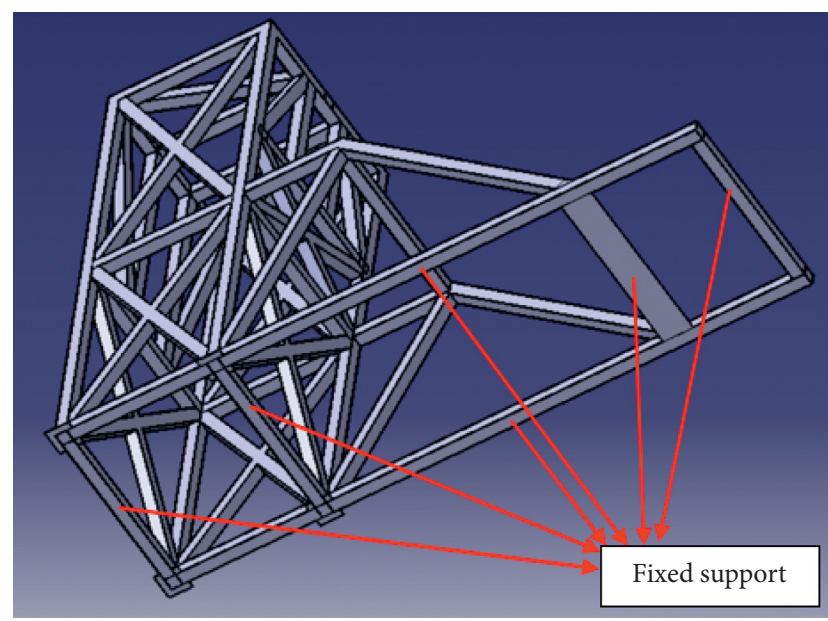

FIGURE 5: Constraints for the test rig analysis.

TABLE 1: Loading condition of a $132-\mathrm{kV}$ composite crossarm under normal conditions.

\begin{tabular}{lcc}
\hline Tie member (tension) & $\begin{array}{c}\text { Main member A } \\
\text { (compression) }\end{array}$ & $\begin{array}{c}\text { Main member B } \\
\text { (compression) }\end{array}$ \\
\hline 15 & 10 & 10 \\
20 & 15 & 15 \\
35 & 20 & 20 \\
40 & 25 & 25 \\
\hline
\end{tabular}

TABLE 2: Specifications of material of creep test rig.

\begin{tabular}{lc}
\hline Items & Specifications \\
\hline Material & Low-carbon steel \\
Tensile strength $(\mathrm{MPa})$ & 766 \\
Yield strength $(\mathrm{MPa})$ & 572 \\
Pipe shape & Square hollow section \\
Pipe size (width/height/thickness) $(\mathrm{mm})$ & $100 / 100 / 1.9$ \\
Total size (width/length/height) $(\mathrm{mm})$ & $1525430 / 4100$ \\
\hline
\end{tabular}

of test rig. Single diagonal, cross-bracing, and V-bracing are the three bracing systems incorporated to the subsequent configurations for comparison purposes through distinguishment from the first model. To improve the existing models, a combination of the three bracing systems was implemented to form a hybrid bracing configuration. Five configurations were simulated under a static structural analysis in ANSYS to verify the mechanical performance and safety conditions. The analysis was also conducted by implementing three specific horizontal forces (one tie and two main members of the mounting areas) with tension and compression forces applied onto the configurations. The outcomes were compared and examined for the selection and fabrication of model.

\section{Deformation Analysis}

Figure 6 depicts the simulation results of each test rig configuration after a range of loading was implemented. The brace frame configuration (a) displays the top horizontal frame of the tower structure that experienced maximum deformation. This is attributed to the applied tension loading from the crossarm, in which the structure was incapable of withstanding the lateral tension load. Furthermore, the deformation experienced by the structure had led to the swaging and distortion of the upper section of the tower. This induced the structure to have a poor stability, which might cause a structural failure. For the single diagonal (b) and cross bracing (c) configurations, the deformation is concentrated at the tie and main member mounting areas but without distorting the upper part of the tower component. This indicates that the additional member of the bracing members had provided an accessibility to excess loading, which is exhibited by the crossarm to be transferred to the ground. Apart from that, the V-bracing (d) and hybrid (e) configurations had lesser deformation occurrence at the tie member mounting area. This improvement was possible due to the capacity of the $\mathrm{V}$-bracing system in reducing the tension yield capacity at the area, thus providing a better structural stability compared to using other types of bracing systems.

The effect of deformation on the bracing system in the test rig configuration was investigated, and the results are depicted in Figure 7. The hybrid configuration in static structural analysis had a noticeable effect on deformation when the static loading was applied. Overall, the installation of bracing system in the brace frame model depicted a trend of reduced deformation reduction effect in the deformation numerically.

The brace frame configuration recorded the highest deformation at the tie member mounted area when a series of tension forces was executed from 15 to $30 \mathrm{kN}$. This indicates that the horizontal frame was insufficient to distribute the force to be grounded in order to maintain the structure integrity. However, the deformation was remarkably reduced after the installation of bracing systems in a form of brace frame model, as shown in the configuration. Figure 7 (a) depicts a decrease in the deformation of a single diagonal configuration based on the previous model, in which the reduction was up to $0.24 \mathrm{~mm}$, almost $80 \%$ reduced at $15 \mathrm{kN}$ of tension loading. The deformation in the series of test rig configurations had decreased in sequence, from single diagonal to cross bracing, V-bracing, and hybrid models between 15 and $30 \mathrm{kN}$ of tension loadings. This was attributed to the properties of the brace frame model that only supports vertical loading; however, it has poor resistance for lateral loads (horizontal forces) [45]. On the other hand, the hybrid configuration depicts a reduction in deformation about $97 \%$, as compared to that of the benchmark model. This improvement was achieved due to the integrated bracing systems in the model that allowed for additional functions and support to provide a better stability to the structure. The combination of these bracing systems has allowed for better bending characteristics, thus stabilising the frame and reducing the tension yield capacity of the mounting areas [42, 46, 47].

According to Figure $7(\mathrm{~b})$, the single diagonal system exhibited the maximum deformation at the main member mounting area from 10 to $25 \mathrm{kN}$ of compression loadings. 


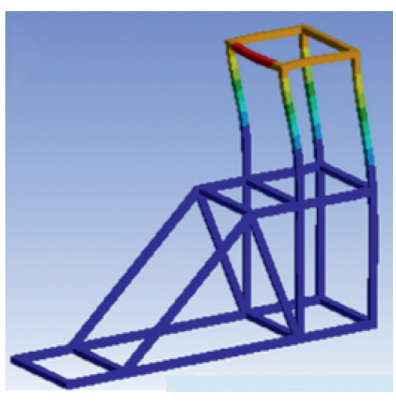

(a)

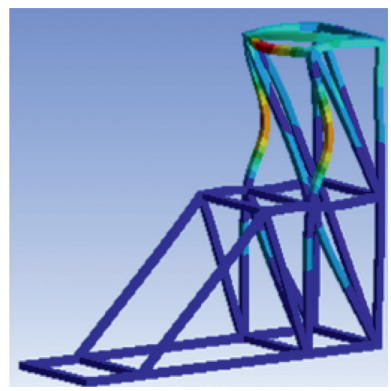

(b)

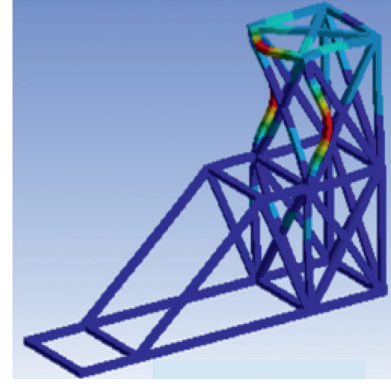

(c)

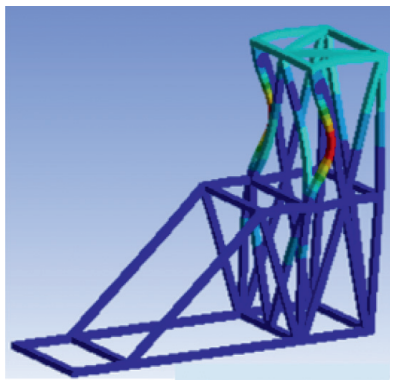

(d)

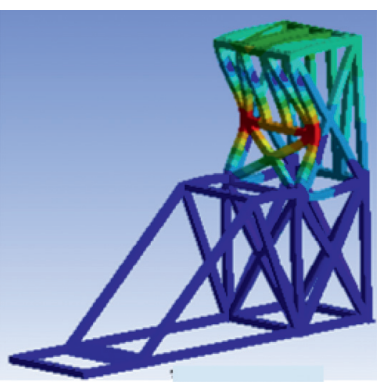

(e)

FIGURE 6: Simulation results comparison of proposed design (a) brace frame, (b) diagonal bracing, (c) cross bracing, (d) V-bracing, and (e) hybrid bracing test rigs.

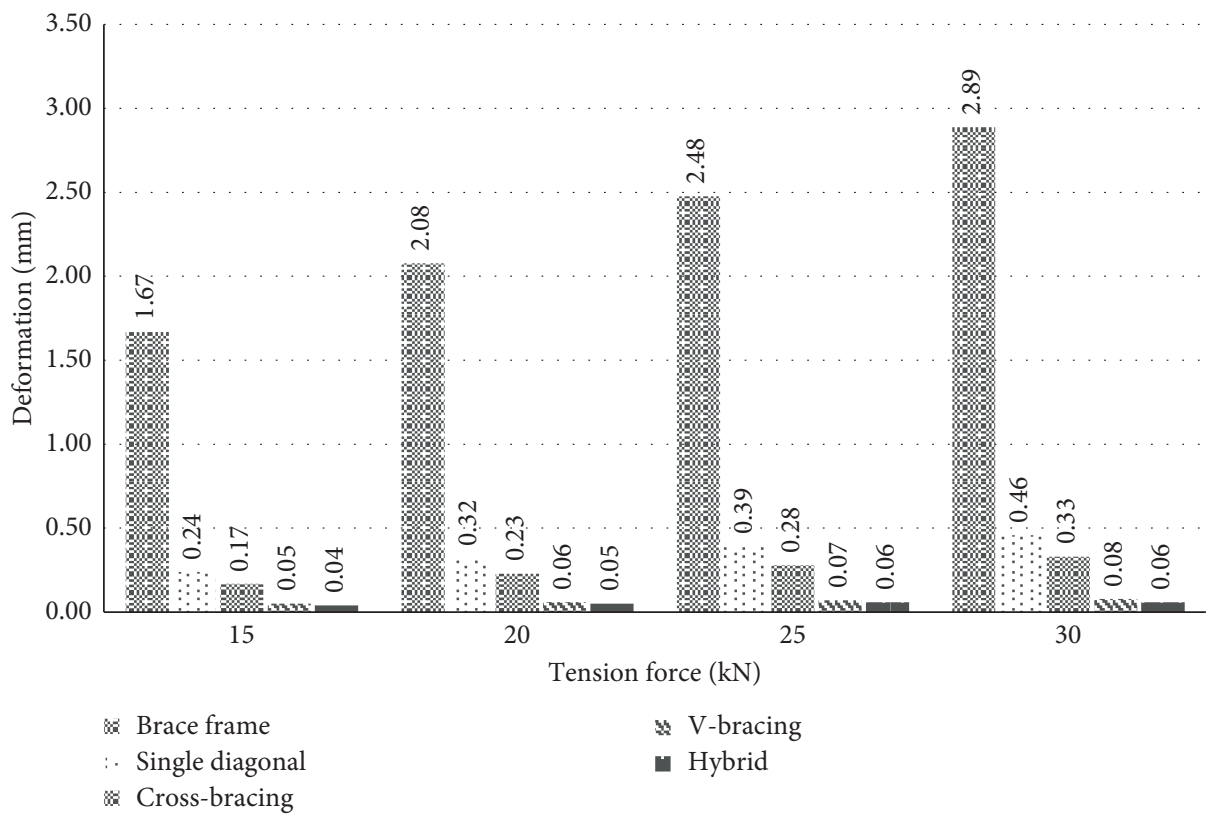

(a)

Figure 7: Continued. 


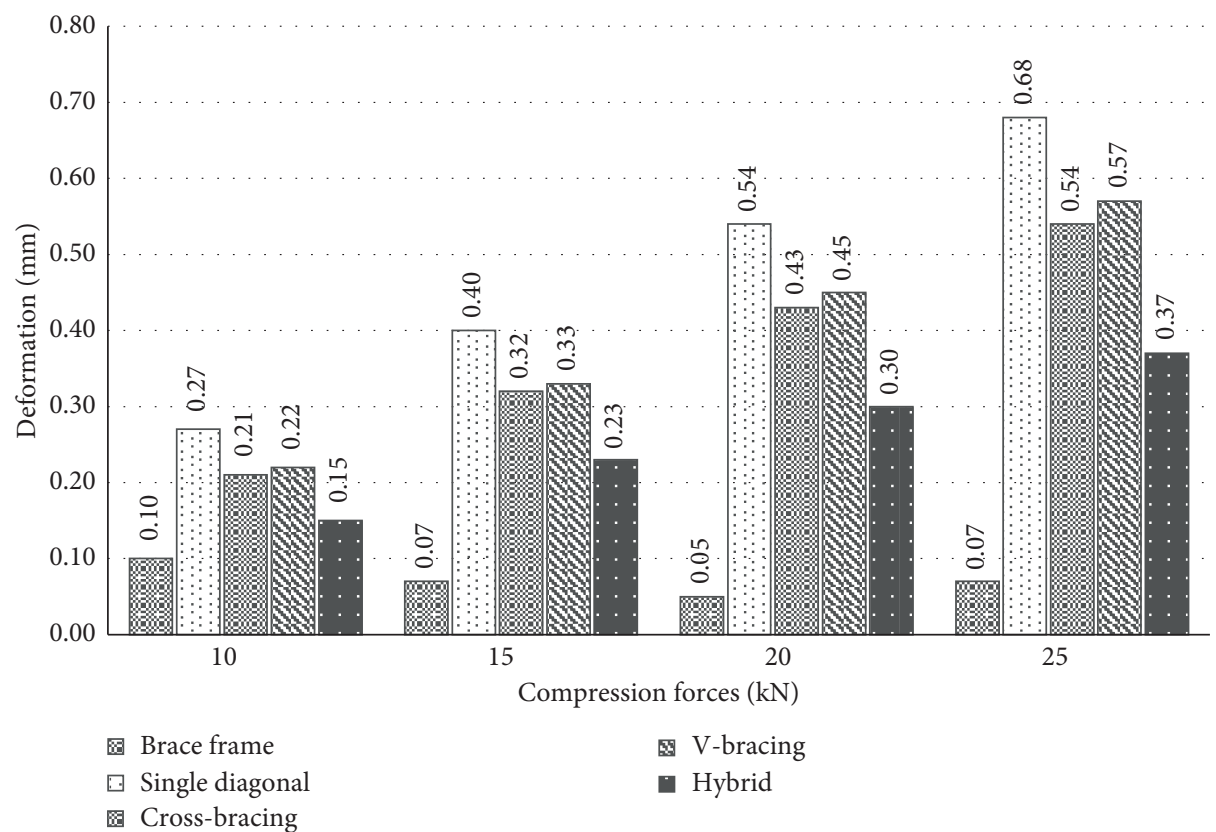

(b)

Figure 7: Deformation analysis at the (a) tie member (tension force) and (b) main member (compression force) joining.

This indicates that the additional members of single diagonal had produced a system of intricate and complex structure instead of providing structure stability. The structure has the ability to perform elastically rather than plastically, following its less energy dissipation capacities in the structure. This induces to a higher deformation occurrence in the model [47]. Meanwhile, the brace frame model performed showed the least deformation when the same force was executed at the same location. This could be explained by the vertical frames of the brace frame model that assisted the excess force to transferring the horizontal force to the foundation. Moreover, the horizontal frame was employed to offer an additional support to the vertical frame and provide sufficient building resistance to the progressive collapse of buildings [31, 46].

\section{Safety Factor Analysis}

Figure 8 shows the safety analysis on various designs of the test rig. Generally, the design of the bracing systems that were embedded in the test rig had shown a visible influence on the safety levels of these configurations.

According to Figure 8(a), a positive effect on the safety analysis was observed immediately after the single diagonal bracing system was introduced. In the simulation analysis, the tension force was applied in a range of 15 to $30 \mathrm{kN}$. The safety factors were analysed at the tie member mounting areas. The simulated graph shows that the safety factor had steadily increased from the brace frame to single diagonal and cross bracing models. Meanwhile, the trend of safety factor had tremendously increased up to its maximum limit in the V-bracing and hybrid models. This attributes display the incorporation of V-bracing model, which connected the tie member, thus directly assisting the structure to decrease its tension yield capacity [31]. The reduction of the capacity eloquently provided a higher mechanical strength, supposedly to increase the safety standards of the test rig. In addition, the hybrid model had remained constant at a maximum safety factor between 15 and $20 \mathrm{kN}$ tension force. Yet, the safety factor values for hybrid configuration had suddenly reduced when the 20 and $30 \mathrm{kN}$ of tension forces were executed. A noticeable change was observed due to the high loading rate, in which the structure was less capable of withstanding the energy absorption from the excess static loading at the crossarm. Meanwhile, the safety factor in the $\mathrm{V}$-bracing experienced was maintained at its maximum in the simulation process. This observation proved that the acting force in the tie member mounting area was distributed with the additional bracing members acting directly onto the foundation of structure [47]. This could have been the improvement of structural stability and integration, causing a mechanical improvement at the critical point.

Figure 8(b) explains the safety factor at the main member mounting areas when a series of compression forces (10 to $25 \mathrm{kN}$ ) were applied. The trends exhibited the same pattern as that of the tie member mounting area, where the safety factor had increased from brace frame to cross bracing models. However, the simulation showed that the safety factor had slightly decreased in the V-bracing model through the application of a series of forces. On the other hand, the hybrid configuration has the highest safety factor at this location, which was 11.25 at $15 \mathrm{kN}$ of compression loading (approximately 152\% increase from the brace frame model). As discussed above, this improvement was possible due to the hybrid design that was made up of three bracing systems (single diagonal, cross bracing, and 


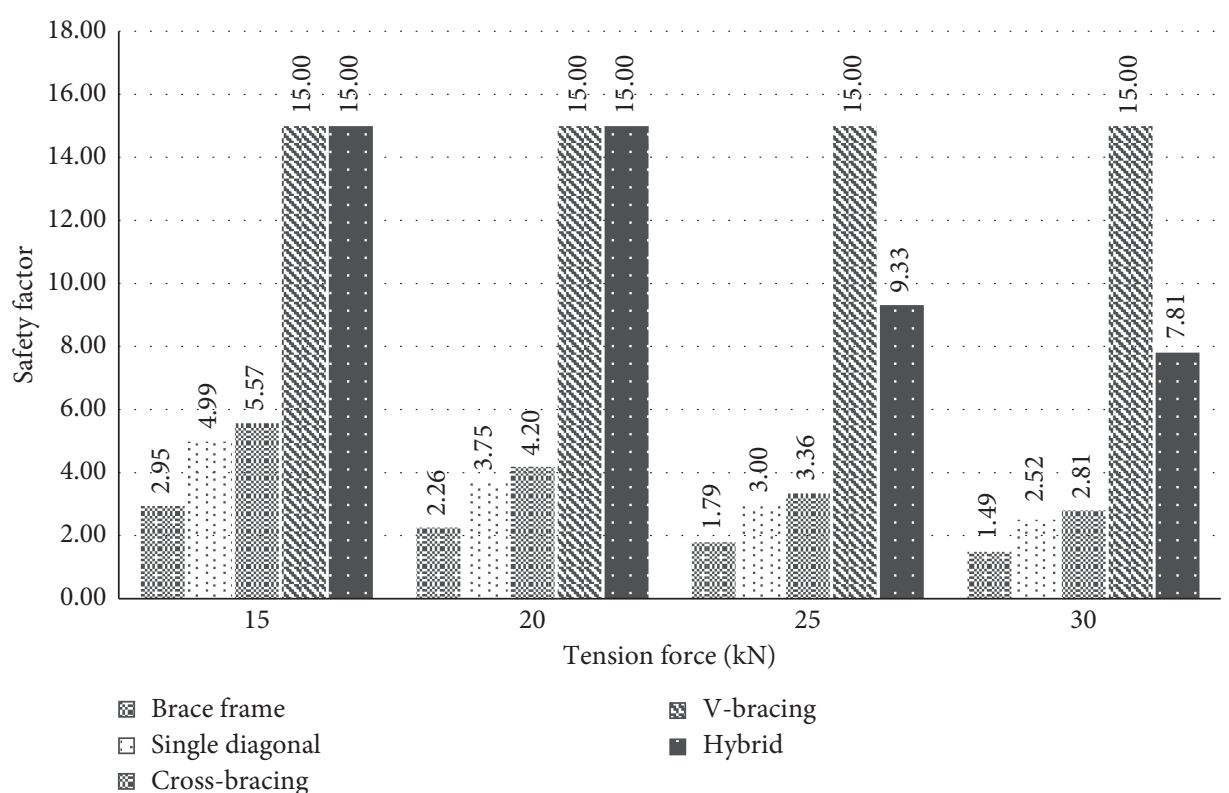

(a)

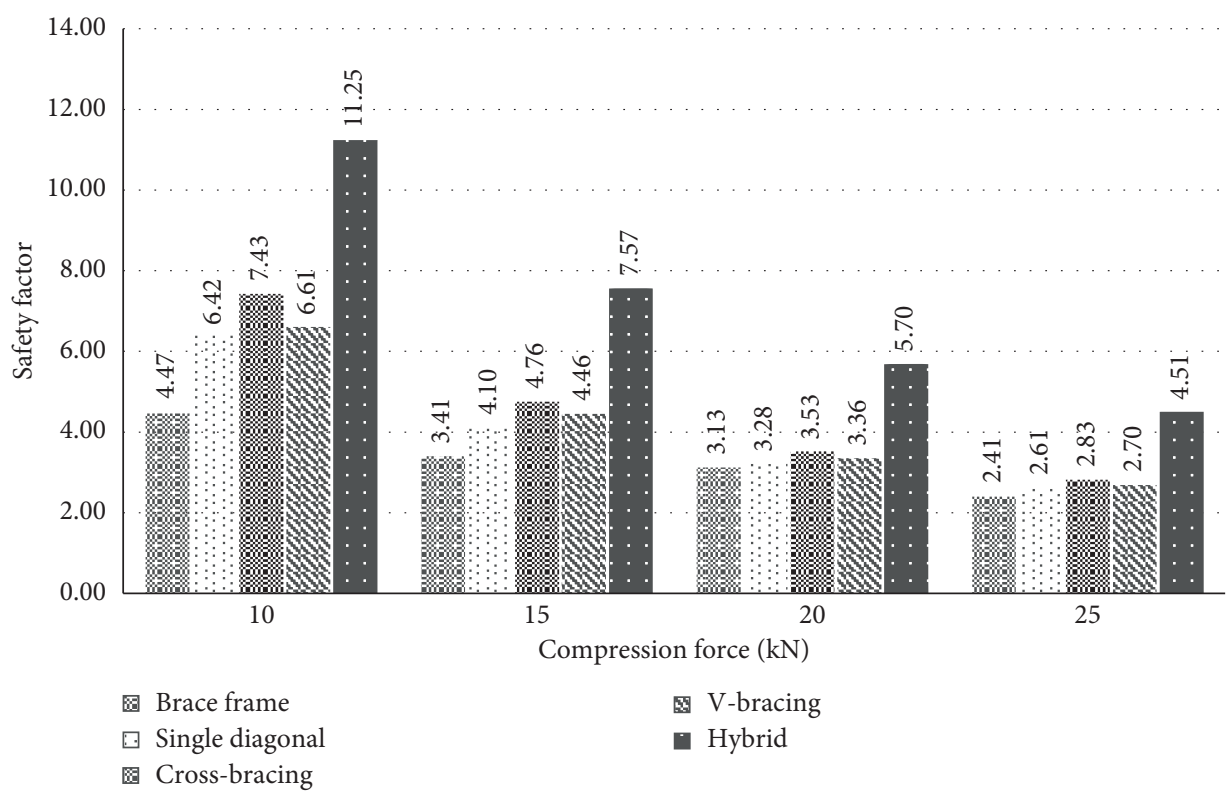

(b)

FIGURE 8: Safety factor analysis at: (a) tie member (tension force) and (b) main member (compression force) joining.

V-bracing), all of which support high compression loading from the main member of the crossarm. The individual bracing system has its own specific functions in maintaining and stabilising the structure. For instance, the single diagonal aids in high compression forces that act in vertical components; cross bracing resists sideway forces depending on the direction of the loading; and V-bracing reduces the tension yield capacity of the tension brace [42, 46-48].

\section{Conclusions}

As a conclusion, the modelling of creep test rig was developed and designed in a configuration of bracing members to support the structure. From the finite element analysis, it was found that the hybrid configuration had shown a significant reduction in deformation as compared to that of the benchmark model. This occurred due to the integrated bracing systems in a single structure model, which in turn 
allowed for additional functions and support to provide a better stability to the structure. The combination of these bracing systems has allowed for better bending characteristics, hence, stabilising the frame and reducing the tension yield capacity of the mounting areas. Moreover, the hybrid design also has the highest safety factor at this location, which was 11.25 at $15 \mathrm{kN}$ of compression loading due to its capability of supporting high compression loading from the main member of the crossarm. Hence, the hybrid model has the optimal outcomes in terms of its mechanical strength and safety performance with respect to the forces applied. This indicates that the integration of the three bracing systems (single diagonal, cross bracing, and V-bracing) was able to stabilise the structure by distributing the loads and restraining the excess forces from the crossarm.

\section{Data Availability}

The simulation data used to support the findings of this study are included within the article.

\section{Conflicts of Interest}

The authors declare no conflicts of interest.

\section{Acknowledgments}

This work was supported by Geran Putra, Universiti Putra Malaysia (9634000) and partly by Universiti Kebangsaan Malaysia (XX-2018-008). The authors were very thankful to Department of Aerospace Engineering, Faculty of Engineering, UPM for providing space and facilities for the project. Moreover, all authors were also very thankful to Jabatan Perkhidmatan Awam (JPA) and Kursi Rahmah Nawawi for providing scholarship award and financial aids to the principal author to carry out this research project.

\section{References}

[1] M. Moutee, M. Fafard, Y. Fortin, and A. Laghdir, "Modeling the creep behavior of wood cantilever loaded at free end during drying," Wood and Fiber Science, vol. 37, no. 3, pp. 521-534, 2005.

[2] A. El-Shafie and S. Aminah, "Dynamic versus static artificial neural network model for masonry creep deformation," Proceedings of the Institution of Civil Engineers-Structures and Buildings, vol. 166, no. 7, pp. 355-366, 2013.

[3] Z. Zhang, J.-L. Yang, and K. Friedrich, "Creep resistant polymeric nanocomposites," Polymer, vol. 45, no. 10, pp. 3481-3485, 2004.

[4] M. R. M. Asyraf, M. R. Ishak, S. M. Sapuan, and N. Yidris, "Woods and composites cantilever beam: a comprehensive review of experimental and numerical creep methodologies," Journal of Materials Research and Technology, 2020.

[5] A. Anand, P. Banerjee, R. K. Prusty, and B. Chandra Ray, "Lifetime prediction of nano-silica based glass fibre/epoxy composite by time temperature superposition principle," IOP Conference Series: Materials Science and Engineering, vol. 338, no. 1, 2018.

[6] M. R. M. Asyraf, M. R. Ishak, S. M. Sapuan, and N. Yidris, "Conceptual design of creep testing rig for full-scale cross arm using TRIZ-Morphological Chart-Analytic Network Process technique," Journal of Materials Research and Technology, vol. 8, no. 6, pp. 5647-5658, 2019.

[7] M. M. Abed, A. El-Shafie, and S. A. Siti, "Creep predicting model in masonry structure utilizing dynamic neural network," Journal of Computer Science, vol. 6, no. 5, pp. 597-605, 2010.

[8] M. R. M. Asyraf, M. R. Ishak, M. R. Razman, and M. Chandrasekar, "Fundamentals of creep, testing methods and development of test rig for the full-scale crossarm: a review," Jurnal Teknologi, vol. 81, no. 4, pp. 155-164, 2019.

[9] J. F. Hunt, H. Zhang, and Y. Huang, "Analysis of cantileverbeam bending stress relaxation properties of thin wood composites," BioResources, vol. 10, no. 2, pp. 3131-3145, 2015.

[10] M. R. M. Asyraf, M. R. Ishak, S. M. Sapuan, and N. Yidris, "Conceptual design of multi-operation outdoor flexural creep test rig using hybrid concurrent engineering approach," Journal of Materials Research and Technology, vol. 9, no. 2, pp. 2357-2368, 2020.

[11] A. El-Shafie, A. Noureldin, M. R. Taha, A. Hussain, and H. Basri, "Performance enhancement for masonry creep predicting model using recurrent neural networks," International Journal Engineering Intelligent Systems, vol. 17, no. 1, pp. 29-38, 2009.

[12] Engineering Department of TNB Transmission Division, Investigation Report on Wooden Crossarm Failure at $132 \mathrm{kV}$ KKSRPPAN L2, 2013.

[13] R. W. Berk, Tenaga Nasional Berhad Transmission Line Design Manual, National Technical Information Service (NTIS), U. S. Department of Commerce, Goodlettsville, Tennessee, 2000.

[14] C. N. A. Jaafar, M. A. M. Rizal, and I. Zainol, "Effect of kenaf alkalization treatment on morphological and mechanical properties of epoxy/silica/kenaf composite," International Journal of Engineering and Technology, vol. 7, no. 4, pp. 258-263, 2018.

[15] C. N. A. Jaafar, I. Zainol, and M. A. M. Rizal, "Preparation and characterisation of epoxy/silica/kenaf composite using hand lay-up method," in Proceedings of the 27th Scientific Conference of the Microscopy Society Malaysia (27th SCMSM 2018), pp. 2-6, Melaka, Malaysia, December 2018.

[16] R. M. Shahroze, M. Chandrasekar, K. Senthilkumar, T. Senthilmuthukumar, M. R. Ishak, and M. R. M. Asyraf, "A review on the various fibre treatment techniques used for the fibre surface modification of the sugar palm fibres,", in Proceedings of the Seminar Enau Kebangsaan, pp. 48-52, Negeri Sembilan, Malaysia, April 2019.

[17] F. Magimay, "Lightning performance of N.E.B.'s $275 \mathrm{kV}$ transmission line," Journal of Institution of Engineers Malaysia, vol. 23, pp. 45-54, 1977.

[18] I. M. Rawi, M. S. A. Rahman, M. Z. A. Ab Kadir, and M. Izadi, "Wood and fiberglass crossarm performance against lightning strikes on transmission towers," in Proceedings of the International Conference on Power Systems Transient (IPST), pp. 1-6, Seoul, Republic of Korea, 2017.

[19] A. C. Liew, "Assessment of the lightning performance of quadruple-circuit transmission lines with steel and wooden crossarms," Electric Power Systems Research, vol. 27, no. 2, pp. 91-97, 1993.

[20] M. Selvaraj, S. Kulkarni, and R. R. Babu, "Analysis and experimental testing of a built-up composite cross arm in a transmission line tower for mechanical performance," Composite Structures, vol. 96, pp. 1-7, 2013.

[21] R. A. Ilyas, S. M. Sapuan, A. Atiqah et al., "Sugar palm (Arenga pinnata [ Wurmb .] Merr) starch films containing sugar palm 
nanofibrillated cellulose as reinforcement: water barrier properties," Polymer Composites, vol. 41, pp. 1-9, 2019.

[22] W. Ashraf, M. R. Ishak, M. Y. M. Zuhri, N. Yidris, A. M. B. Yaacob, and M. R. M. Asyraf, "Investigation of different facesheet materials on compression properties of honeycomb sandwich composite," in Proceedings of the Seminar Enau Kebangsaan, pp. 129-132, Negeri Sembilan, Malaysia, April 2019.

[23] A. N. Johari, M. R. Ishak, Z. Leman et al., "Fabrication and cut-in speed enhancement of savonius vertical axis wind turbine (SVAWT) with hinged blade using fiberglass composites," in Proceedings of the Seminar Enau Kebangsaan, pp. 978-983, Negeri Sembilan, Malaysia, April 2019.

[24] J. M. G. Rabelo, J. S. Becho, M. Greco, and C. A. Cimini Jr., "Modeling the creep behavior of GRFP truss structures with positional finite element method," Latin American Journal of Solids and Structures, vol. 15, no. 2, 2018.

[25] U. Schümann, F. Barcikowski, M. Schreiber, H. C. Kärner, and J. M. Seifert, "FEM calculation and measurement of the electrical field distribution of HV composite insulator arrangements," in Proceedings of the 39th Cigre Session, pp. 25-30, Paris, France, August 2002.

[26] M. F. Sá, A. M. Gomes, J. R. Correia, and N. Silvestre, "Creep behavior of pultruded GFRP elements-part 1: literature review and experimental study," Composite Structures, vol. 93, no. 10, pp. 2450-2459, 2011.

[27] S.-C. Yen and F. L. Williamson, "Accelerated characterization of creep response of an off-axis composite material," Composites Science and Technology, vol. 38, no. 2, pp. 103-118, 1990.

[28] Z. Ehtiatkar, S. Basiri, and N. Amin, "Mechanical design and analysis of innovative integrated circuit test socket," in Proceedings of the 2011 IEEE Regional Symposium on Micro and Nanoelectronics, RSM 2011 - Programme and Abstracts, IEEE, Sabah, Malaysia, pp. 65-69, January 2011.

[29] A. Nadhirah, D. Mohamad, M. Zainoodin et al., "Properties of fiberglass crossarm in transmission tower-a review," International Journal of Applied Engineering Research, vol. 12, no. 24, pp. 15228-15233, 2017.

[30] N. A. Rahman and S. R. S. Abdullah, "Assessment tool of course learning outcomes for mechanical design of process equipment," Procedia-Social and Behavioral Sciences, vol. 102, pp. 116-121, 2013.

[31] D. M. Patil and K. K. Sangle, "Seismic behaviour of different bracing systems in high rise 2-D steel buildings," Structures, vol. 3, pp. 282-305, 2015.

[32] M. D’Aniello, G. La Manna Ambrosino, F. Portioli, and R. Landolfo, "The influence of out-of-straightness imperfection in physical theory models of bracing members on seismic performance assessment of concentric braced structures," Structural Design of Tall and Special Buildings, vol. 24, no. 3, pp. 176-197, 2015.

[33] R. Tremblay, "Inelastic seismic response of steel bracing members," Journal of Constructional Steel Research, vol. 58, no. 5-8, pp. 665-701, 2002.

[34] A. d. Souza Pippi, J. K. Junior, and M. A. Silva Pinheiro, "Evaluation of dynamic characteristics in a transmission line latticed steel tower," Procedia Engineering, vol. 199, pp. 122127, 2017.

[35] C. Lu, X. Ma, and J. E. Mills, "Modeling of retrofitted steel transmission towers," Journal of Constructional Steel Research, vol. 112, pp. 138-154, 2015.
[36] C. Lu, Y. Ou, X. Ma, and J. E. Mills, "Structural analysis of lattice steel transmission towers: a review," Journal of Steel Structures \& Construction, vol. 2, no. 1, pp. 1-11, 2016.

[37] Q. Shu, Z. Huang, G. Yuan, W. Ma, S. Ye, and J. Zhou, "Impact of wind loads on the resistance capacity of the transmission tower subjected to ground surface deformations," Thin-Walled Structures, vol. 131, pp. 619-630, 2018.

[38] K. Shea and I. F. C. Smith, "Improving full-scale transmission tower design through topology and shape optimization," Journal of Structural Engineering, vol. 132, no. 5, pp. 781-790, 2006.

[39] H.-D. Zheng, J. Fan, and X.-H. Long, "Analysis of the seismic collapse of a high-rise power transmission tower structure," Journal of Constructional Steel Research, vol. 134, pp. 180-193, 2017.

[40] C. Lu, X. Ma, and J. E. Mills, "Cyclic performance of reinforced legs in retrofitted transmission towers," Archives of Civil and Mechanical Engineering, vol. 18, no. 4, pp. 16081625, 2018.

[41] Q. Shu, G. Yuan, Z. Huang, and S. Ye, "The behaviour of the power transmission tower subjected to horizontal support's movements," Engineering Structures, vol. 123, pp. 166-180, 2016.

[42] G. Abdollahzadeh, H. Faghihmaleki, and H. Esmaili, "Comparing Hysteretic Energy and inter-story drift in steel frames with V-shaped brace under near and far fault earthquakes," Alexandria Engineering Journal, vol. 57, no. 1, pp. 121-130, 2018.

[43] C. Shah, "Mesh discretization error and criteria for accuracy of finite element solutions," in Proceedings of the Ansys Users Conference, Pittsburgh, PA, USA, 2002.

[44] S. Sinaie, A. Heidarpour, and X. L. Zhao, "Mechanical properties of cyclically-damaged structural mild steel at elevated temperatures," Construction and Building Materials, vol. 52, pp. 465-472, 2014.

[45] J. N. Richardson, G. Nordenson, R. Laberenne, R. Filomeno Coelho, and S. Adriaenssens, "Flexible optimum design of a bracing system for façade design using multiobjective genetic algorithms," Automation in Construction, vol. 32, pp. 80-87, 2013.

[46] G. F. Giaccu, “An equivalent frequency approach for determining non-linear effects on pre-tensioned-cable crossbraced structures," Journal of Sound and Vibration, vol. 422, pp. 62-78, 2018.

[47] A. Kanyilmaz, "Role of compression diagonals in concentrically braced frames in moderate seismicity: a full scale experimental study," Journal of Constructional Steel Research, vol. 133, pp. 1-18, 2017.

[48] O. Pourabdollah, F. Farahbod, and F. R. Rofooei, "The seismic performance of K-braced cold-formed steel shear panels with improved connections," Journal of Constructional Steel Research, vol. 135, pp. 56-68, 2017. 